Article

\title{
Investigation of Precipitable Water Vapor Obtained by Raman Lidar and Comprehensive Analyses with Meteorological Parameters in Xi'an
}

\author{
Yufeng Wang, Liu Tang, Jing Zhang, Tianle Gao, Qing Wang, Yuehui Song and Dengxin Hua * \\ School of Mechanical and Precision Instrument Engineering, Xi'an University of Technology, \\ Xi'an 710048, China; wyfecnu@126.com; (Y.W.); tangliu37@163.com (L.T.); zhangjing@xaut.edu.cn (J.Z.); \\ nardus88@163.com (T.G.); wangqing@163.com (Q.W.); songyuehuii@xaut.edu.cn (Y.S.) \\ * Correspondence: dengxinhua@xaut.edu.cn
}

Received: 28 May 2018; Accepted: 14 June 2018; Published: 17 June 2018

\begin{abstract}
To evaluate the potential of Raman lidar observations for measuring precipitable water vapor $(\mathrm{PWV}), \mathrm{PWV}$ variations and distribution characteristics were investigated in $\mathrm{Xi}^{\prime}$ an $\left(34.233^{\circ} \mathrm{N}\right.$, $108.911^{\circ} \mathrm{E}$ ), and its comparisons with meteorological parameters were also analysed. Comparisons of lidar PWV with radiosonde PWV verified the ability and accuracy of using Raman lidars for PWV measurements. The diurnal and monthly variation trends in PWV in different layers are first discussed via the statistical analysis of lidar data from November 2013 to July 2016; different proportions of PWV were found in different layers, and the PWV in each layer presented a slight diurnal change trend and consistent seasonal variation, which was relatively rich in summer, less so in spring and autumn, and relatively deficient in winter. Furthermore, correlation analyses between lidar PWV and meteorological parameters are explored. Water vapor pressure and surface temperature revealed the same inter-seasonal oscillation of $\mathrm{PWV}$, with a correlation coefficient of $\sim 0.90$. However, incomplete synchronization was found between PWV and relative humidity and precipitation parameters. Higher humidity appeared in the late summer and the beginning of autumn of each year, which was also the case for precipitation and precipitation efficiency. In addition, atmospheric water vapor density profiles and the obtained PWV by Raman lidar are discussed employing a rainfall case, and a comprehensive analysis with meteorological parameters is undertaken. The intensifying characteristics of vertical change in water vapor and the accumulation of PWV in the lower troposphere can be captured by lidar before the onset of rainfall. In contrast to the obvious diurnal change trend, such meteorological parameters as relative humidity, water vapor pressure, and dew-point temperature difference are accompanied with stable trends with a change rate of close to 0 in the rainfall processes; they also show high correlated variations with lidar PWV. Thus, with the advantage of lidar detection, investigation of water vapor profiles and PWV by Raman lidar, and the comprehensive correlation analyses with synchronic meteorological parameters can prove to be good indications of rainfall.
\end{abstract}

Keywords: precipitable water vapor (PWV); Raman lidar; meteorological parameters

\section{Introduction}

Atmospheric water vapor plays an important role in hydrological processes, atmospheric circulation, and weather systems. Precipitable water vapor (PWV) is defined as a vertically integrated water vapor column within a layer, and it is the most active component in the global hydrological cycle, which makes water vapor an important factor affecting regional climate change, water balance and energy balance [1-3]. Research on temporal and spatial distributions of atmospheric water vapor and 
precipitable water vapor not only aid in studies of global and regional climate change, cloud formation and precipitation process, but also provide a theoretical basis for atmospheric water resources.

In recent years, researchers at home and abroad have realized the retrieval and estimation of PWV by ground-based observations or space-based remote sensing methods employing radiosondes, GPS, solar photometers, meteorological station data and lidars. Radiosondes can potentially be used to estimate PWV, and are also used to provide reference data for comparisons with PWV retrieved from Aeronet sun photometers, GPS, and MODIS products [4,5]. Ground-based GPS observations have high temporal resolution, long-term stability, and are independent of all weather conditions. The accuracy of estimated PWV obtained from ground-based GPS observations has been investigated in many studies [6-8]. Sun photometers are an important tool for atmospheric research and meteorological observations and have advantages in studying the optical and physical properties of aerosol particles. By employing direct radiation analyses of solar forcing, aerosol size distributions, PWV, optical thicknesses and ozone contents can also be obtained and used to calibrate satellite remote sensing results $[9,10]$.

With the development of laser technology and Raman spectroscopy, Raman lidars have been successfully used to measure atmospheric temperature, water vapor, and aerosols [11-13]. Vibrational Raman scattering signals from water vapor molecules $\left(\mathrm{H}_{2} \mathrm{O}\right)$ and nitrogen molecules $\left(\mathrm{N}_{2}\right)$ have been widely used in the detection of water vapor profiles [14,15]. Many ground-based Raman lidar systems currently exist around the world, and significant achievements have been made in the measurement of atmospheric water vapor and aerosol profiles [16-18]. At present, atmospheric water vapor mixing ratio profiles can be obtained up to the top of the troposphere by employing Raman lidars; they can also be used to estimate PWV content.

Xi'an city $\left(34.233^{\circ} \mathrm{N}, 108.911^{\circ} \mathrm{E}\right)$, which is located in the northwest inland area of China, is characterized by an arid to semi-arid monsoon climate, and is also an important watershed that affects the climate of northern and southern China. It is of value to study the temporal and spatial distributions of water vapor and PWV in $\mathrm{Xi}^{\prime}$ an and to determine the response of the semi-arid area to climate change. Thus, we have focused on the distribution and variations in the characteristics of lidar PWV and a correlation analysis with meteorological parameters to further evaluate the potential of Raman lidar observations for measuring PWV. The Raman lidar system involved was developed at the Xi'an University of Technology in 2013, and the system configuration and retrieval method will be briefly introduced in Section 2. The lidar PWV from the water vapor mixing ratio profiles is first compared with radiosonde PWV, and the correlation analyses used to verify the ability and accuracy are described. More than 2000 sets of Raman lidar data from 2013 to 2016 were employed in a statistical analysis to obtain the diurnal and monthly mean PWV, and the seasonal variation and proportion of PWV in different layers are investigated in Section 3. The lidar PWV and meteorological station data are also compared in Section 4, and the correlations of PWV with vapor pressure, surface temperature and humidity are presented. In Section 5, a comprehensive analysis of lidar PWV with meteorological parameters during a rainfall process is undertaken, and the vertical change of atmospheric water vapor before and after rainfall is discussed. Further correlation analyses were also conducted to study the prediction of rainfall.

\section{Lidar Data and Its Evaluation}

\subsection{Raman Lidar System}

The high temporal resolution PWV data used in this study were obtained using the established ultraviolet Raman lidar system at the Xi'an University of Technology. The Raman lidar system has become a routine tool for simultaneously measuring the atmospheric temperature, water vapor, relative humidity and aerosol profile over Xi'an, China, since 2013 [12]. A schematic diagram of the Raman lidar system is presented in Figure 1. The system employs a pulsed Nd:YAG laser as a light source. The laser operates at a frequency-tripled wavelength of $354.7 \mathrm{~nm}$ and has a $20 \mathrm{~Hz}$ 
repetition rate, energy output of $150 \mathrm{~mJ}$, and $9 \mathrm{~ns}$ full width at half maximum (FWHM) pulse duration. Returned signals are collected using a $600 \mathrm{~mm}$ Newtonian telescope and then coupled into a multimode optical fiber and guided into a spectroscopic box; all signals are detected using photomultiplier tubes (PMTs).

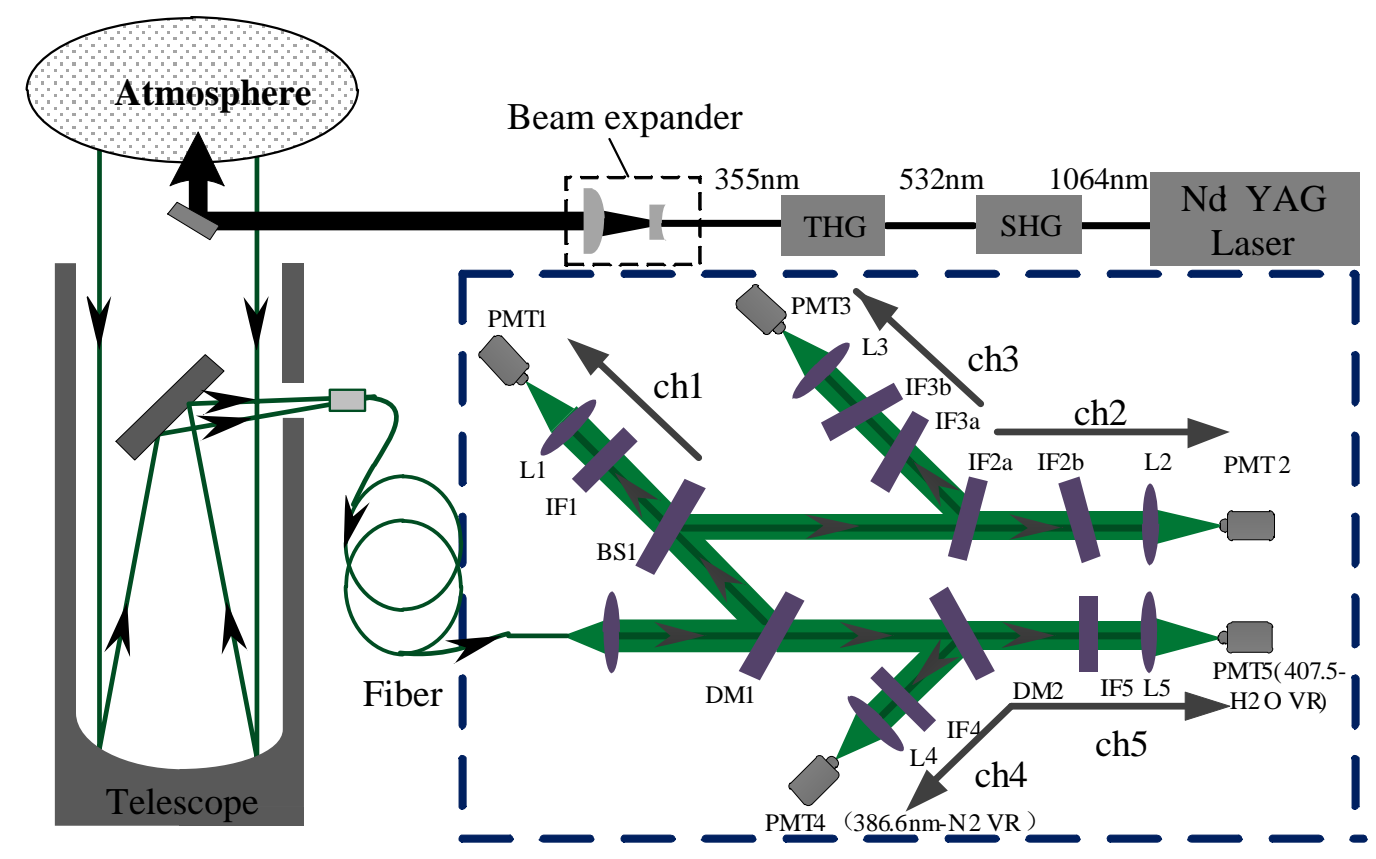

Figure 1. Schematic diagram of the Raman-Mie lidar system: DM-dichroic mirror; BS-beam splitter; IF-interference filter; L-lens.

A set of dichroic mirrors (DMs) and narrow-band interference filters (IFs) is used to construct a high-efficiency polychromator, which divides the return signals into five channels. Channel 1 is used for the detection of elastic Mie-Rayleigh signals, and channels 2 and 3 are used for the extraction of two pure rotational Raman signals for retrieving atmospheric temperature profiles. Channels 4 and 5 are used to detect the vibrational Raman signals of nitrogen and water vapor molecules in order to retrieve atmospheric water vapor mixing ratio profiles.

The DMs require an incident angle of $15^{\circ}$ and have dichroic characteristics. They transmit the spectra in a certain wavelength range with a peak transmittance of $>98 \%$, and almost completely reflect other wavelengths; IFs are used to select the wavelengths of interest and to reduce the background radiation and block the strong elastic signals.

The reflection of DM1 is used to reflect the lidar returns with spectral wavelengths shorter than $365 \mathrm{~nm}$ to build the channels of the elastic scattering signal and the rotational Raman signals. A beam splitter (BS) is used to divide this portion of the lidar returns into two parts, of which one part, with $30 \%$ of the energy, is used to build the elastic channel, and the other, with $70 \%$ of the energy, is used to build the channels of the pure rotational Raman signals. Double-interference filters are utilized, where IF2a and IF2b are at incident angles of $5^{\circ}$, with the central wavelength of $353.9 \mathrm{~nm}$, bandwidths of 0.6 $\mathrm{nm}$, and peak transmissions of 0.5 , to extract the low-quantum-number pure rotational Raman signals. IF3a and IF3b are at incident angles of $7^{\circ}$, with the central wavelength of $352.5 \mathrm{~nm}$, bandwidths of 1.1 $\mathrm{nm}$ and peak transmissions of 0.5 to extract the high-quantum-number pure rotational Raman signals.

The transmission of DM1 serves to build the channels which detect the vibrational Raman signals. The vibrational Raman signals of nitrogen and water vapor are separated by DM2, which transmits the spectral wavelengths greater than $400 \mathrm{~nm}$. Fine extraction of these two spectra is executed by IF4 and IF5, with the central wavelength of $386.7 \mathrm{~nm}$ and $407.5 \mathrm{~nm}$, and bandwidth of $1 \mathrm{~nm}$ and $5 \mathrm{~nm}$, respectively. The combination of DMs and IFs achieves fine extraction of the required 
central-wavelength return signals in channels $1-5$ and a sufficient rejection rate of the elastic scattering light in the Raman channels.

\subsection{Rereieval Method for Lidar Data}

According to its definition, atmospheric water vapor mixing ratio $w(z)$ can be retrieved using the ratio of the Raman signals of water vapor and nitrogen molecules, and given as [14]:

$$
w(z)=0.485 \times \frac{P_{H}(z)}{P_{N}(z)} \cdot \frac{k_{N}}{k_{H}} \cdot \frac{\sigma_{N}(\pi)}{\sigma_{H}(\pi)} \cdot \exp \left\{\int_{0}^{z}\left[\alpha_{\lambda_{H}}\left(z^{\prime}\right)-\alpha_{\lambda_{N}}\left(z^{\prime}\right)\right] d z^{\prime}\right\},
$$

where the subscripts $\mathrm{H}$ and $\mathrm{N}$ denote $\mathrm{H}_{2} \mathrm{O}$ and $\mathrm{N}_{2}$ molecules respectively, $P$ is the output power of the channel, $\sigma$ the Raman scattering cross section, $\alpha_{\lambda}$ is the extinction coefficient at wavelength $\lambda$, and $k$ the system efficiency factor, including the optical efficiency and electrical efficiency of the system. $k_{N} / k_{H}$ is the system constant, which can be calibrated by comparison with radiosonde data at the same height.

The mixing ratio $q$ (units: $\mathrm{g} / \mathrm{kg}$ ) is a function of water vapor mixing ratio, and given as:

$$
q(z)=\frac{w(z)}{w(z)+1}
$$

PWV is defined as the vertically integrated water vapor column (units: $\mathrm{mm}$ ) within a layer and can be calculated as [6]:

$$
\mathrm{PWV}=\frac{1}{\mathrm{~g} \rho} \int_{\mathrm{p}_{0}}^{\mathrm{p}} \mathrm{qdp}=\frac{1}{\mathrm{~g} \rho} \sum_{\mathrm{i}=1}^{\mathrm{n}} \overline{\mathrm{q}} \Delta \mathrm{p},
$$

where $\mathrm{p}_{0}$ and $\mathrm{p}$ are the atmospheric pressures (units: Pascals) at the layer's upper and lower boundaries, respectively, $g$ is the acceleration due to gravity $\left(9.806 \mathrm{~ms}^{-2}\right)$, and $\rho$ is vapor density. Consequently, lidar PWV can be obtained from the atmospheric mixing ratio profiles.

\subsection{PWV Evaluation by Lidar and Radiosonde}

To validate lidar PWV observations, the water vapor profiles obtained using the lidar are first calibrated using radiosonde data from the local Meteorological Bureau of $\mathrm{Xi}^{\prime}$ an. In addition, the obtained lidar PWV are compared with those obtained by radiosonde in this section. Radiosonde PWV estimates can be obtained from the mixing ratio q, which is calculated by [8]:

$$
\mathrm{q}=\frac{0.622 \mathrm{e}}{\mathrm{p}-0.378 \mathrm{e}^{\prime}}
$$

$q$ is related to the vapor pressure $e$, which is a function of dew-piont temperature $t_{d}\left({ }^{\circ} \mathrm{C}\right)[8]$ :

$$
\mathrm{e}=6.112 \times \mathrm{e}^{\frac{17.62 \mathrm{t}_{\mathrm{d}}}{243.12+\mathrm{t}_{\mathrm{d}}}},
$$

and therefore, the profile of geopotential height and dew-piont temperature at pressure levels can be used to assess the radiosonde PWV.

Figure 2 shows a measurement example for atmospheric water vapor performed under clear weather conditions at 20:00 CST (Chinese standard time) on 16 November 2013, and comparisons with radiosonde data are also shown. Figure 2a shows the range-corrected power signals of lidar returns, including Mie-Rayleigh scattering, nitrogen, and water vapor Raman scattering signals. The pulsed energy was $150 \mathrm{~mJ}$, and the integration time of water vapor measurements was $15 \mathrm{~min}$. All the raw data were collected with an altitude resolution of $3.75 \mathrm{~m}$ and were smoothed with a sliding window length of 75-150 m. All the heights in this study are relative to the ground level. By comparing the shapes, Mie-Rayleigh scattering and nitrogen Raman scattering signal are more smooth and attenuated with increasing height, and the water vapor Raman scattering signal are decreased with 
drastic change. The retrieved water vapor mixing ratio profile is shown in Figure $2 b$ as a solid line. It should be explained that the complete overlap region of the system starts from approximately $0.5 \mathrm{~km}$, and the lidar return signal was simply discarded in the first few hundred meters. Obvious increases in water vapor density can be found at $6-8 \mathrm{~km}$ and $12-16 \mathrm{~km}$, indicating the occurrence of water vapor layers that are not associated with the cloud layer because no enhancement is observed from the range-corrected signals of the elastic Mie-Rayleigh scattering signals. Also, radiosonde data at 20:00 CST obtained from the local Meteorological Bureau of Xi'an ( $\sim 8 \mathrm{~km}$ from the lidar $)$ are plotted for comparison, as the dashed line. It can be seen that the retrieved water vapor density profiles are in very good agreement with the radiosonde data below the height of $16 \mathrm{~km}$, especially in the regions of water vapor layers. The bias is less than $0.5 \mathrm{~g} / \mathrm{kg}$ and is close to 0 at high levels, as shown in Figure $1 \mathrm{c}$.
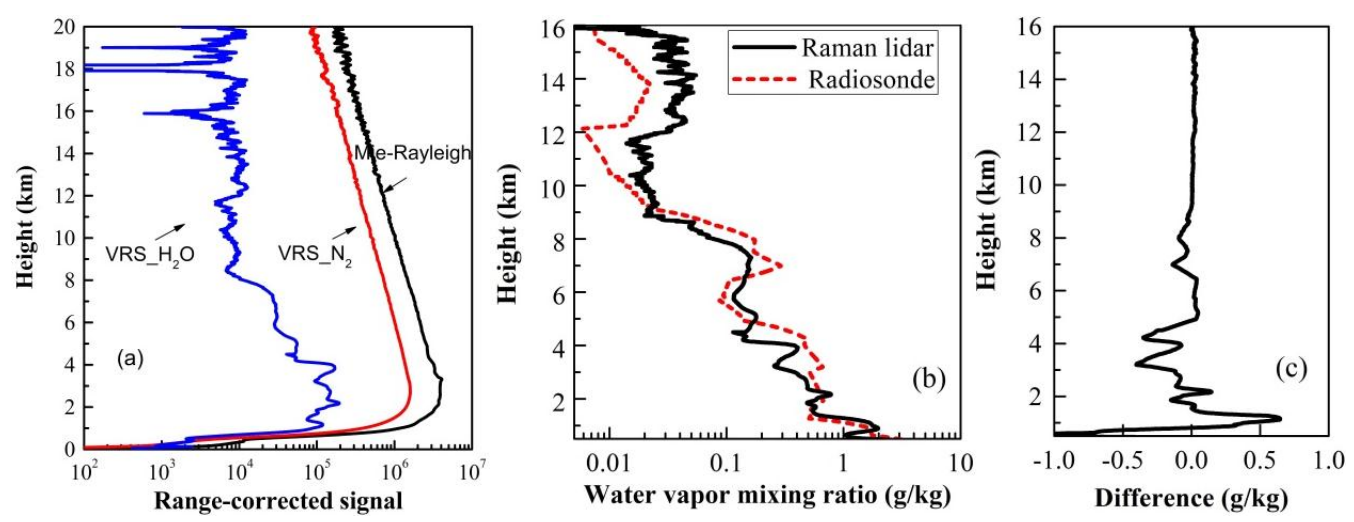

Figure 2. The measured Range-corrected signal of lidar returns, the retrieved water vapor density profile, and comparisons with radiosonde data taken at 20:00 CST on 16 November 2013.

To further evaluate the lidar PWV, 60 sets of water vapor profiles under clear weather condition were compared with those obtained via radiosonde. The altitude interval is mainly within the height range of $0.5-5 \mathrm{~km}$, also including several sets of those within $0.5-10 \mathrm{~km}$. The integration time for water vapor measurement is $15 \mathrm{~min}$; thus, water vapor data by Raman lidar taken from 19:45 to 20:15 CST is involved in the comparisons. The scatter plot in Figure 3 displays the correlation between the lidar and radiosonde PWV. The abbreviation mm means the unit of millimeter. After undertaking a least squares fit to the points, good agreement was found among the Raman lidar and radiosonde water vapor measurements. The correlation coefficient for the comparison results was approximately 0.99 , which suggests that Raman lidar are highly comparable with radiosonde PWV, and could be useful for measuring PWV with high precision.

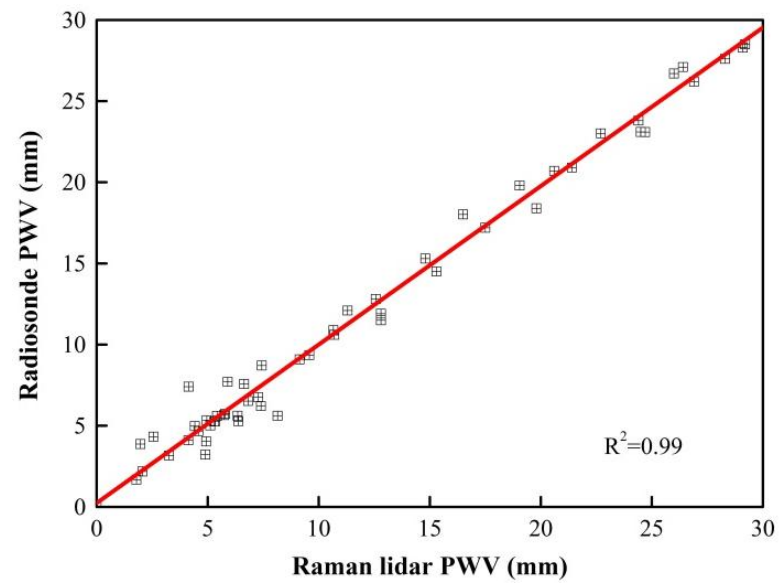

Figure 3. Scatter plot of correlation between Lidar PWV and radiosonde PWV. 


\section{Analysis and Discussion of Lidar PWV}

To investigate the characteristics and distribution of PWV, we conducted a statistical analysis of lidar PWV from 2013 to 2016 in this section. The PWV in different layer and its mean PWV are involved in further study of the diurnal, monthly, and seasonal variation trend in PWV over Xi'an.

\subsection{Distribution of Daily PWV in Layers}

To investigate the characteristics of the temporal and spatial variations in PWV over Xi'an, we conducted a stratified study of PWV in each layer and analyzed the proportions of PWV in different layers. To investigate the temporal and spatial variation of water vapor, continuous observations were conducted from 20:30 CST on 15 November to 06:00 on 16 November under clear weather conditions, with an interval of $15 \mathrm{~min}$ and spatial resolution of $3.75 \mathrm{~m}$. Figure 4 shows a time-height-indicator (THI) diagram of the atmospheric water vapor mixing ratio during the process. Regarding the vertical variation, the water vapor mixing ratio was found to vary greatly with height, and significant stratification can be observed. The water vapor was mainly concentrated below $4 \mathrm{~km}$, whereas the water vapor mixing ratio was minimal between 4 and $6 \mathrm{~km}$. The atmospheric water vapor in the bottom layer also showed an increasing trend from 01:00 CST to the next morning. It first increased at 2-3 km from 01:00 to 04:00 CST and then increased at the bottom of layer to a value of $4 \mathrm{~g} / \mathrm{kg}$, indicating a process whereby water vapor settled in the early morning.

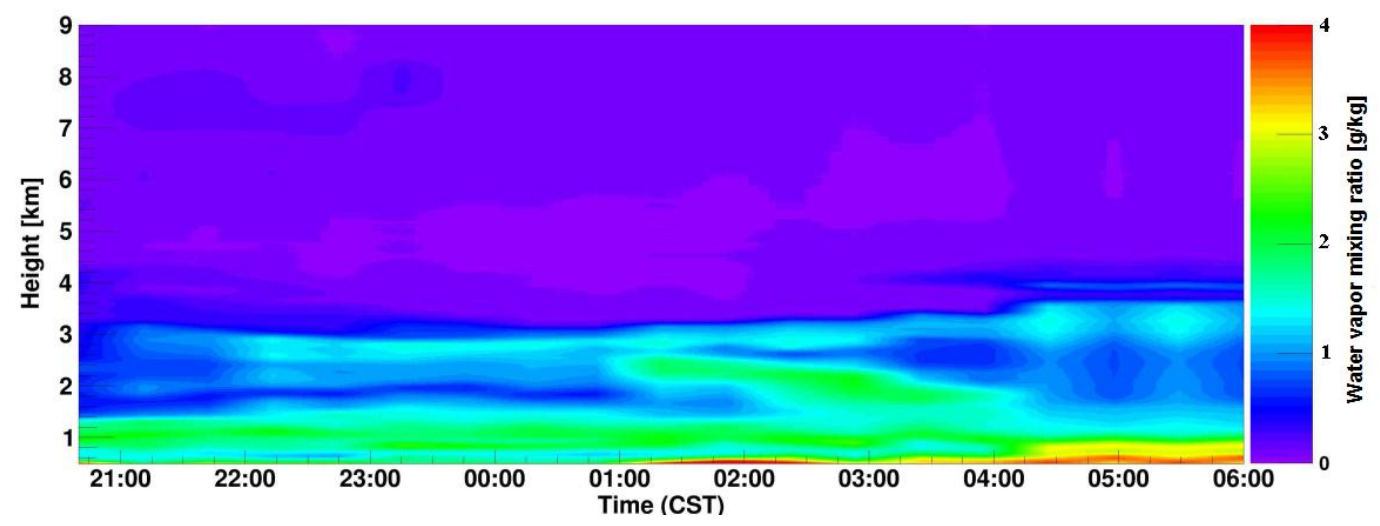

Figure 4. THI plot of water vapor mixing ratio profiles during 20:30-06:00 LST on 16 November 2016.

Using the temporal and spatial distributions of water vapor, we calculated the total PWV and that in each layer employing Equation (3). The proportions of the PWV in different layers were also obtained, as shown in Figure 5. Considering the rare precipitable water up to $200 \mathrm{hPa}, 200 \mathrm{hPa}$ was generally considered as the top layer in our calculations, and the height range from the ground to $200 \mathrm{hPa}$ was divided into the following six layers: near ground-700 hPa, $700-600 \mathrm{hPa}, 600-500 \mathrm{hPa}$, $500-400 \mathrm{hPa}, 400-300 \mathrm{hPa}$, and 300-200 hPa, which correspond to heights ranging from 0.5 to $3.15 \mathrm{~km}$, $3.15-4.4 \mathrm{~km}, 4.4-5.8 \mathrm{~km}, 5.8-7.4 \mathrm{~km}, 7.4-9.5 \mathrm{~km}$, and 9.5-12 km, respectively. Figure 5a shows the temporal variations in lidar PWV in each layer; the proportions of PWV in different layers are also shown in Figure 5b. The total precipitable water content was relatively stable and averaged $14 \mathrm{~mm}$ before 01:30 CST, and then gradually increased and reached a maximum value of $\sim 16 \mathrm{~mm}$, as shown by the black curve. The red curve presents the variations in the PWV in the first layer from the ground to $700 \mathrm{hPa}$; the averaged PWV in that layer was $\sim 9 \mathrm{~mm}$, increased gradually from 22:30 CST, and then decreased in the early morning. The proportion of the first layer accounted for $55 \%$ at 20:30 CST, increased and reached 75\% from 22:30 to 01:30, and then decreased during 04:30-05:30 CST. The PWV of the second layer is shown to have had an average value of $\sim 2 \mathrm{~mm}$, presented a decreasing trend from 19:30 to 00:30 CST and an increasing trend from 00:30 to 05:30 CST, as shown by the blue curve. Its proportion was significantly lower and ranged from $10 \%$ to $20 \%$ with time. In addition, for the 
PWV of the third layer from 600 to $500 \mathrm{hPa}$, it clearly decreased with time, the average value was $1 \mathrm{~mm}$, and the proportion ranged from $12 \%$ to $3 \%$.
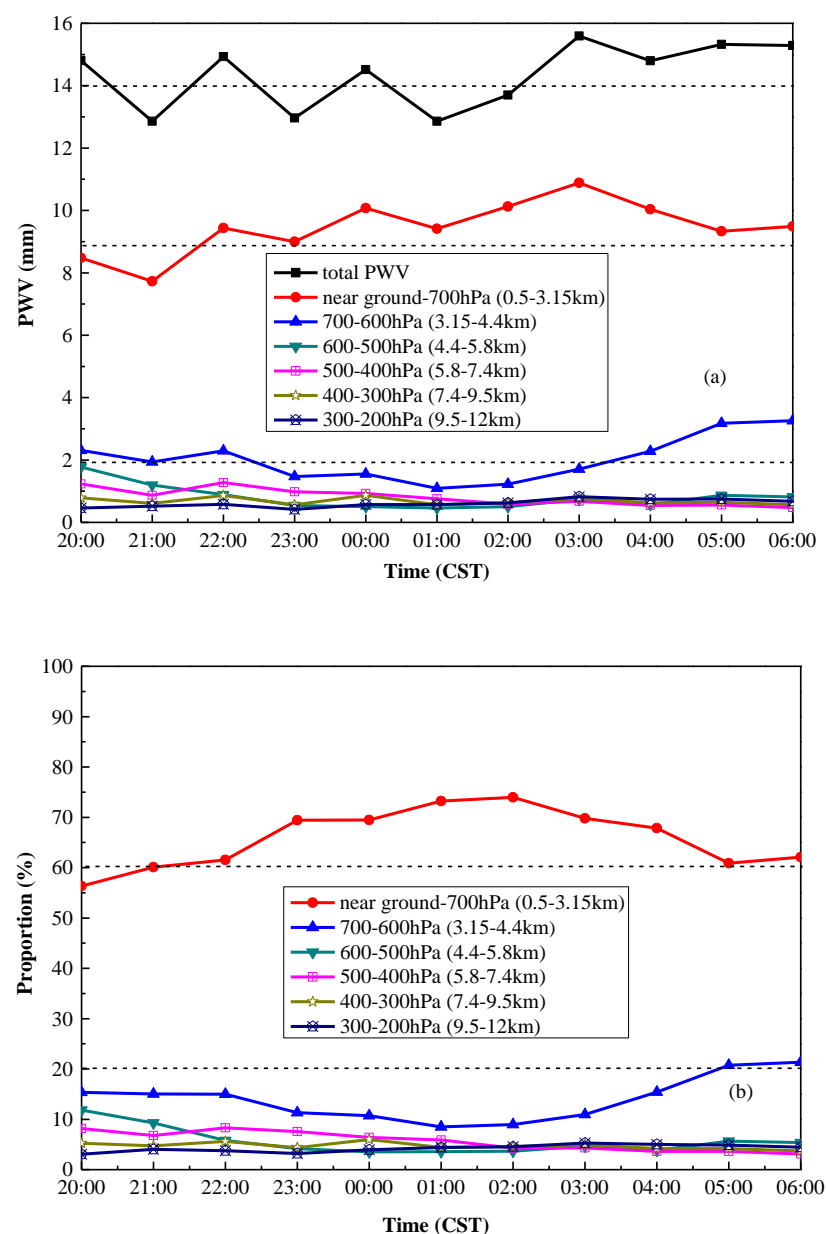

Figure 5. Temporal and spatial variations in PWV; (a) PWV in each layer; (b) its proportion in each layer.

The PWV in other layers and the corresponding proportions in the total precipitable water content with increasing height were also analyzed. It was found that the PWV in $500-400 \mathrm{hPa}, 400-300 \mathrm{hPa}$, and 300-200 hPa layers showed the same declining trend with time, and the proportion declined as well, ranging from $8 \%$ to $3 \%$. Therefore, the PWV in each layer changed with time and presented a slight diurnal change trend, and the proportion of PWV differed in different layers, decreasing rapidly with increasing height, which was indicative of the high temporal and spatial characteristics of water vapor. In addition, the PWV from near ground to $500 \mathrm{hPa}$ accounted for $82-93 \%$ from the night to the early morning, and therefore, most of the total precipitable water vapor was concentrated in the height range from the ground to $500 \mathrm{hPa}$.

\subsection{Distribution of Seasonal PWV in Layers}

We will now discuss the seasonal PWV characteristics over Xi'an; the total PWV in different layers is the primary focus of this section. Based on more than 2000 water vapor profiles collected between 20:00 and 22:00 CST under clear weather conditions, we performed a statistical analysis of PWV in each layer, the daily average values of which were used to obtain the monthly averages. Figure 6 shows the monthly variations in the total PWV from 2013 to 2016. An obvious seasonal variation trend can be observed; the total PWV began to rise in February, underwent a growth period from February to 
June, and reached a maximum from July to September. The total PWV was highest in summer, with an average value of $24 \mathrm{~mm}$ and was smallest in February, averaging $2 \mathrm{~mm}$.

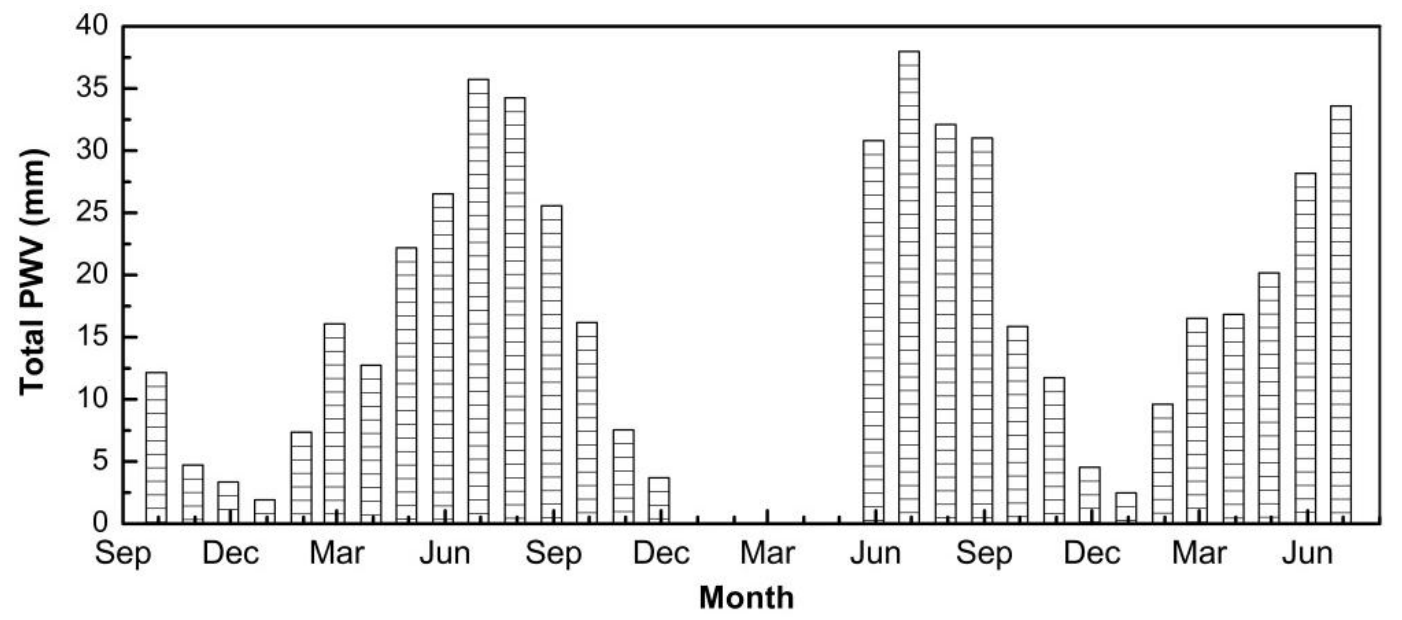

Figure 6. Seasonal variations in the total PWV from September 2013 to July 2016.

In addition, we undertook a concrete analysis of PWV in different layers to investigate their seasonal variation trends. The results in layers from the near ground-700 $\mathrm{hPa}, 700-500 \mathrm{hPa}$, and $500-200 \mathrm{hPa}$, are provided as illustrations herein, and a histogram is shown in Figure 7. On the whole, they showed a consistent seasonal variation which was relatively rich in summer, less so in spring and autumn, and relatively deficient in winter. In addition, in view of the PWV values, different PWV contents existed in different layers. Taking July 2014 as an example, the average PWV from the near ground-700 hPa was $25 \mathrm{~mm}$, and those from 700 to $500 \mathrm{hPa}$ and 500-200 hPa were $8 \mathrm{~mm}$ and $5 \mathrm{~mm}$, respectively. The seasonal PWV in different layers also presented a consistent distribution of proportions with daily variations.
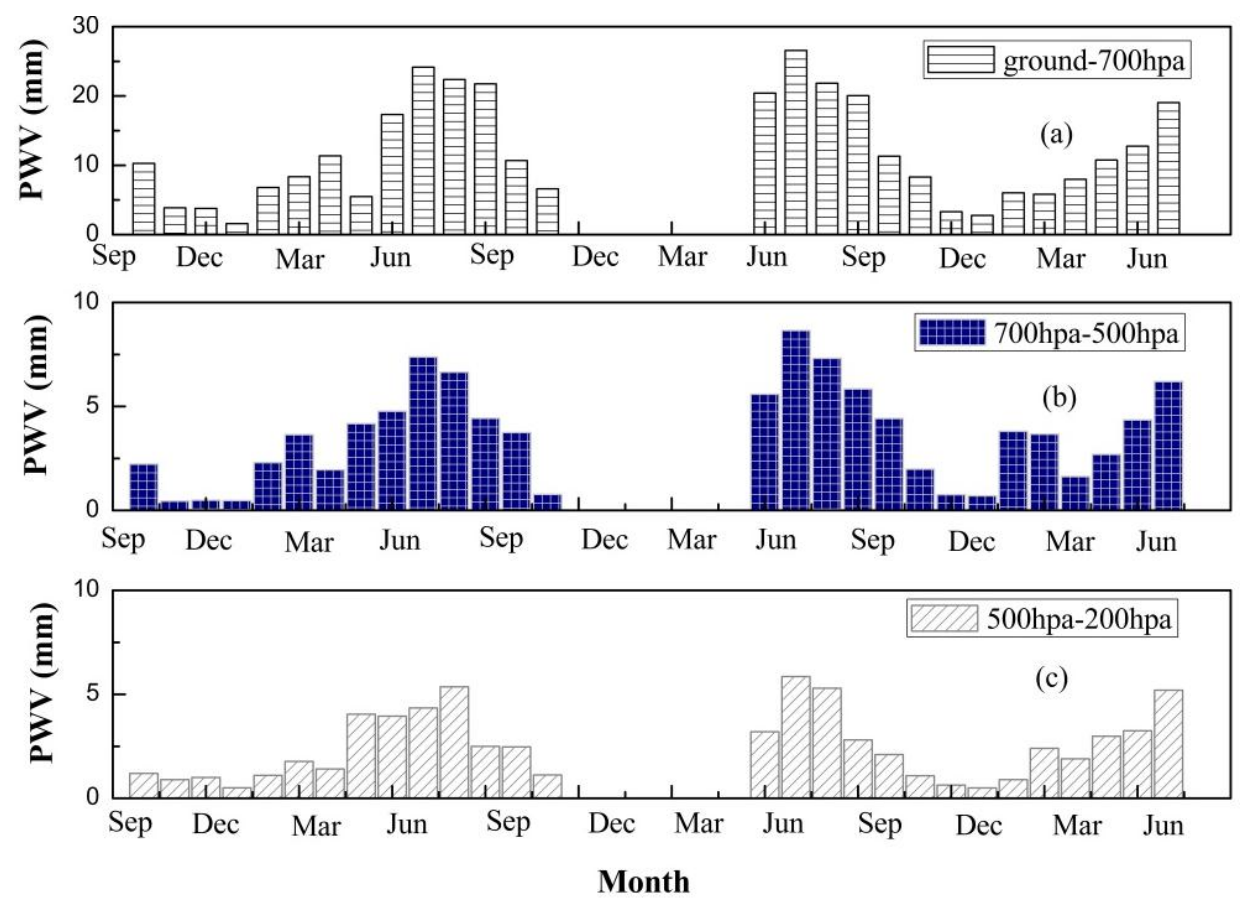

Figure 7. Seasonal variations in PWV in different layers from September 2013 to July 2016. 


\section{Investigation of PWV and Meteorological Data}

The ground meteorological data have important significance for the prediction and assessment of precipitable water vapor, and the amount and variation of precipitable water vapor also influence precipitation to a certain extent. In this section, we focus on the correlations between the lidar PWV and meteorological data from meteorological stations such as surface temperature, water vapor pressure, and relative humidity for PWV and the precipitation parameters.

\subsection{Investigation of PWV and Surface Meteorological Data}

To investigate the correlation between PWV and the surface meteorological data, more than 1000 sets of water vapor profiles from the Raman lidar and the meteorological data from the ground weather stations were simultaneously employed in the statistical analysis. The daily PWV was averaged from the water vapor data at height ranges from the near ground to $700 \mathrm{hPa}$ at 19:30-20:30 using the Raman lidar. The same statistical means were also used for the meteorological data, including those of surface temperature, water vapor pressure and relative humidity.

Figure 8 displays the variations in lidar PWV, surface temperature, water vapor pressure, and relative humidity for 1000 days. The red curves correspond to the lidar PWV (mm), and the blue curves correspond to surface temperature, water vapor pressure, and relative humidity in Figure 8a-c, respectively. Figure 8a presents the comparisons of PWV and surface temperature, which show a consistent variation trend between them. The PWV increased due to the increasing temperature, and declined due to decreasing temperature. By comparisons of PWV and water vapor pressure, we can also see from Figure $8 \mathrm{~b}$ that the lidar PWV and water vapor pressure were more consistent in their general trends. However, there was no certain trend in relative humidity. It varied greatly ranging from $20 \%$ to $90 \%$, and there was no obvious variation trend. Therefore, no consistent variation trend was observed between the PWV and relative humidity, as shown in Figure 8c. We also further examined the regression analysis between PWV and the above meteorological data, as shown in Figure 9. A positive linear regression was observed between PWV, surface temperature, and water vapor pressure, with correlation coefficients of 0.894 and 0.866 , respectively; they were both significant at the 0.01 level, indicating that there are strong positive correlations between PWV and surface temperature and water vapor pressure. However, the correlation of PWV with the relative humidity is relatively low. The main reasons can be considered as follows: (1) as a function of water vapor and temperature, relative humidity does not depend entirely on water vapor; (2) PWV reflects the effect of vertical water vapor and surface temperature, not just horizontal advection of humidity.

To undertake a better analysis of the seasonal correlations between them, we performed a statistical analysis of lidar PWV and the above ground meteorological parameters. The monthly mean PWV values were obtained from the daily averages, which was also the case for the statistical mean values of the meteorological data. Figure 10 displays the monthly and seasonal variation trends in PWV and ground meteorological data. The PWV in $\mathrm{Xi}^{\prime}$ an presented an obvious seasonal variation trend; it was higher during summer and lower in winter. The temperature and PWV showed consistent seasonal variation trends; the PWV increased due to the increasing monthly mean temperature in summer and declined due to the decreasing monthly mean temperature in winter. In addition, the monthly mean variation in water vapor pressure was similar to that of $P W V$, and clearly showed the same inter-seasonal transition change. There was higher water vapor pressure and PWV in spring and summer and lower water vapor pressure and PWV in autumn and winter, and the PWV increased and reached its maximum in summer when the vapor pressure had risen. However, a not completely consistent seasonal trend was observed in relative humidity. The monthly mean humidity varied from $40 \%$ to $80 \%$ in $\mathrm{Xi}^{\prime}$ an, and the annual averaged humidity was approximately $56 \%$. Higher humidity occurred in the late summer and beginning of autumn of each year, and the humidity reached its minimum value in spring and winter. The accumulation of water vapor in summer might have contributed to the increase in humidity in autumn. 

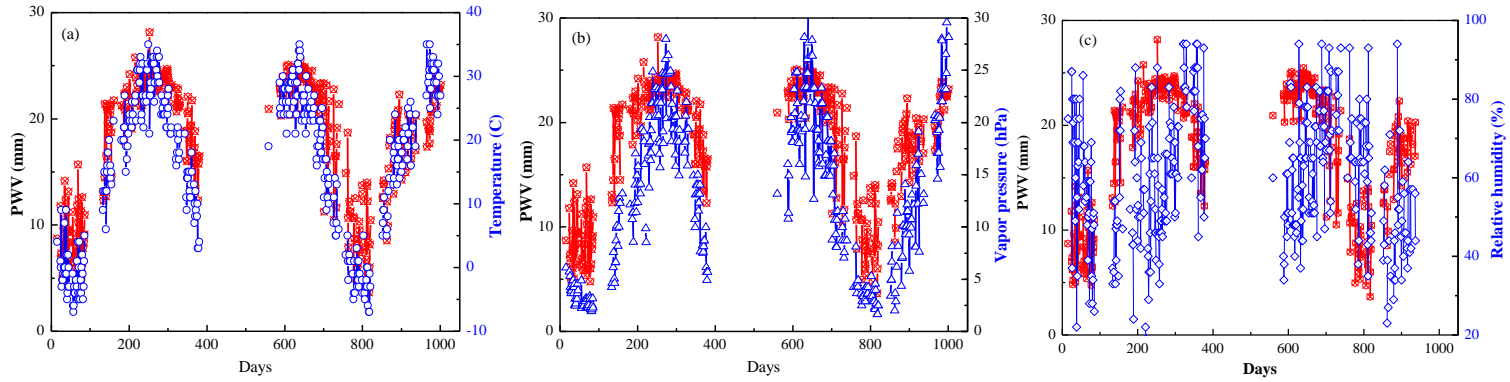

Figure 8. Variations between PWV and atmospheric temperature, vapor pressure and humidity. (a) temperature; (b) vapor pressure; (c) relative humidity.
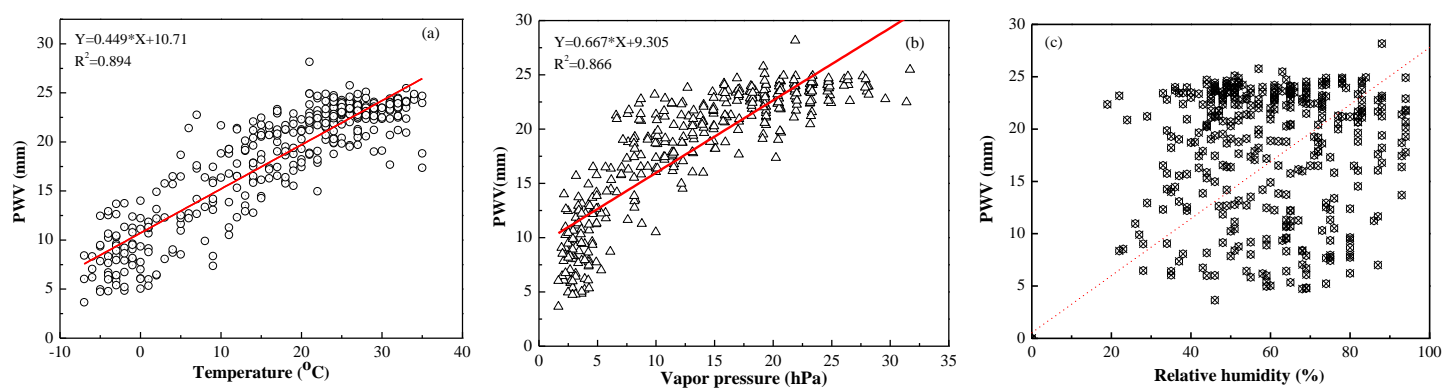

Figure 9. Correlations between PWV and atmospheric temperature, vapor pressure and humidity. (a) temperature; (b) vapor pressure; (c) relative humidity.

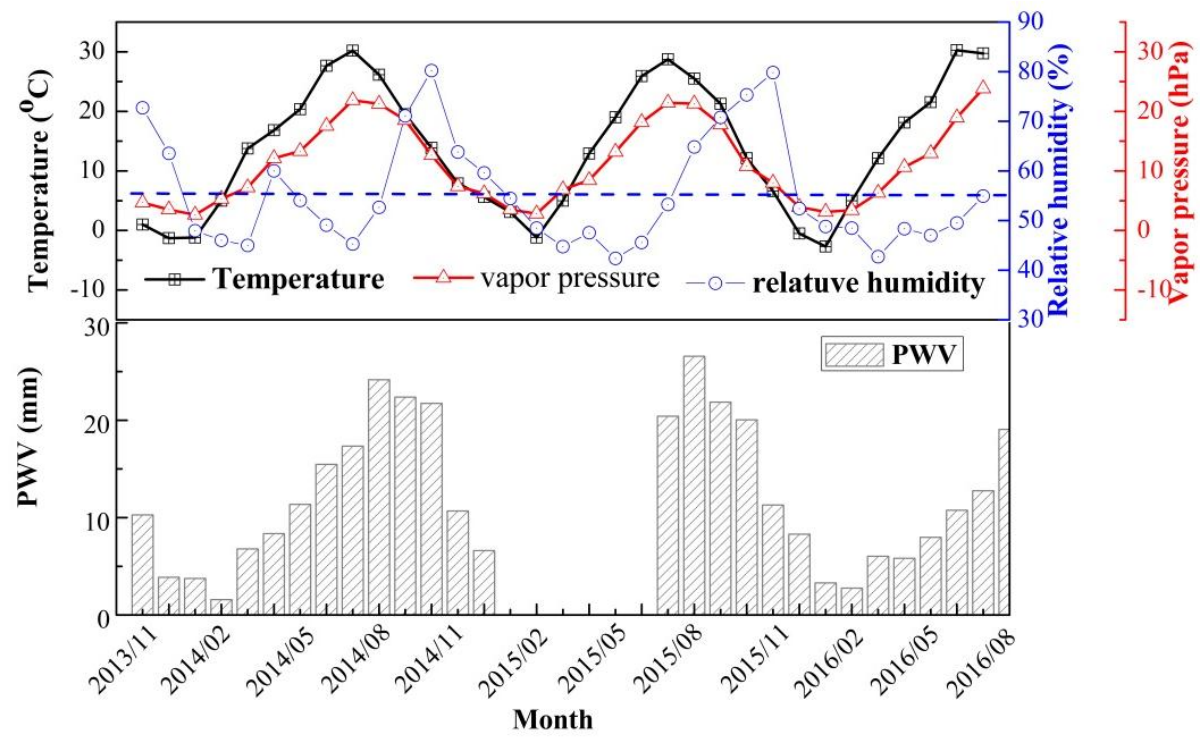

Figure 10. The seasonal variation trends in PWV and ground meteorological elements.

\subsection{Investigation of $P W V$ and Precipitation}

The amount and variation of PWV influence precipitation to a certain extent. The monthly mean values of lidar PWV and the precipitation parameters are considered in this section. The scatter plot and histogram in Figure 11 display the variations in precipitation and precipitation efficiency over $\mathrm{Xi}^{\prime}$ an, and the lidar PWV are also shown. We can clearly see that they show the same inter-seasonal transition change with PWV. Regarding precipitation, the monthly mean precipitation was larger in summer and autumn and lower in winter and spring; a maximum value of $247 \mathrm{~mm}$ occurred 
in September 2014, and the average annual precipitation was $50 \mathrm{~mm}$ in Xi'an. The precipitation efficiency was also found to be high in spring and summer and low in winter and autumn, similar to precipitation. The monthly mean precipitation efficiency was relatively low (less than 5\%), except that the maximum efficiency of 12\% occurred in September 2014 and July 2016. Therefore, it was found that the precipitation in Xi'an was mainly concentrated in summer and autumn (June-September), accounting for more than half of the total annual precipitation, and the precipitation efficiency was lower than $2 \%$ in December to February, indicating extremely small rainfall, which caused the dry climate in winter in Xi'an.

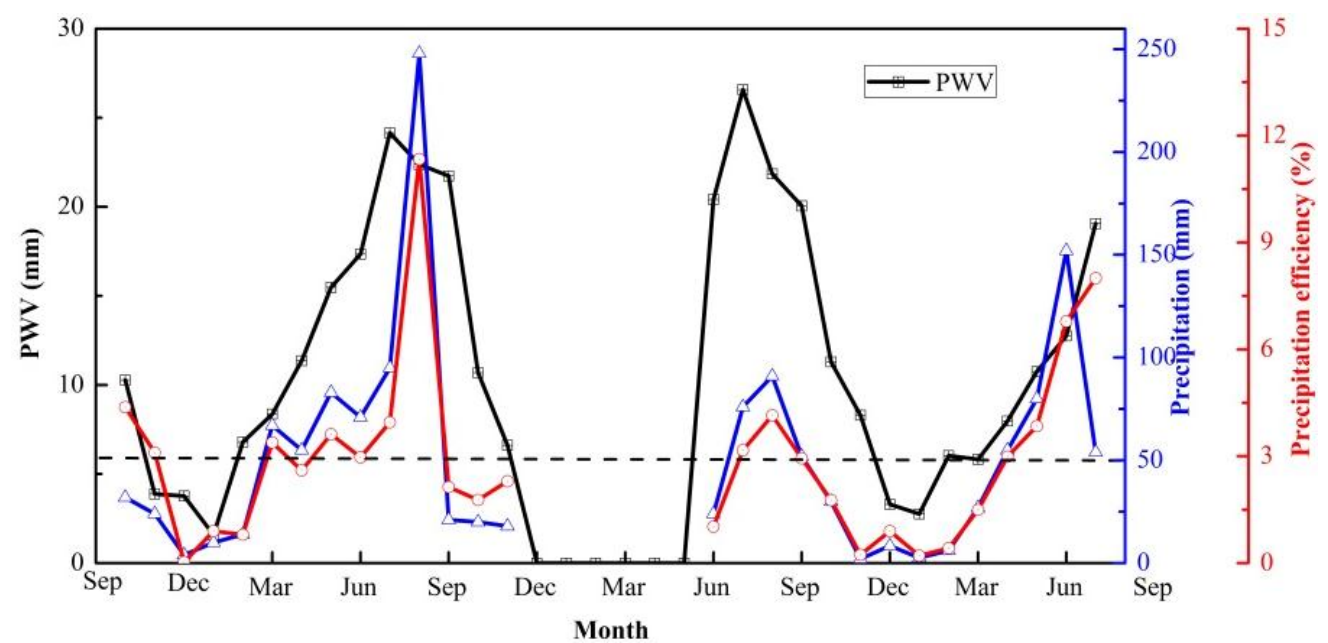

Figure 11. The seasonal variations in averaged PWV, precipitation and precipitation efficiency.

The comparison results also revealed inconsistent phenomena between lidar PWV and precipitation. For example, the monthly PWV reached a maximum value of $23.42 \mathrm{~mm}$ in July 2015, but the average precipitation in that month was only $24 \mathrm{~mm}$. This inconsistency exists because the PWV does not directly determine whether precipitation occurs but just represents the potential for atmospheric precipitation. Although there is a certain correlation between precipitation and PWV in the area, total PWV is only one of the necessary conditions for precipitation. In general, large precipitation requires the transportation and supplementation of water vapor and does not merely depend on local precipitable water vapor.

\section{Case Study}

Horizontal and vertical distributions of humidity and related parameters such as relative humidity, vapor pressure, and PWV are important factors during rainfall. In this section, time series of lidar PWV, vapor pressure, humidity, and dew-point temperature difference (DTD) are compared in detail to investigate the evolution trends and the correlation among them during a rainfall case of 1-10 October 2015 that passed over Xi'an.

Taking advantage of lidar detection, water vapor density profiles are compared and analyzed before and after rainfall. Figure 12 showed the atmospheric water vapor density profiles on 3, 5, 7, and 8 October, of which the front 2 days correspond to those before rainfall, and the latter 2 days correspond to those after rainfall. The atmospheric water vapor profile at 19:30-21:15 CST at nighttime is used to investigate the spatial and temporal distribution of water vapor below $4 \mathrm{~km}$. It can be clearly seen that obvious difference was found in the vertical change in water vapor profiles before and after rainfall. 

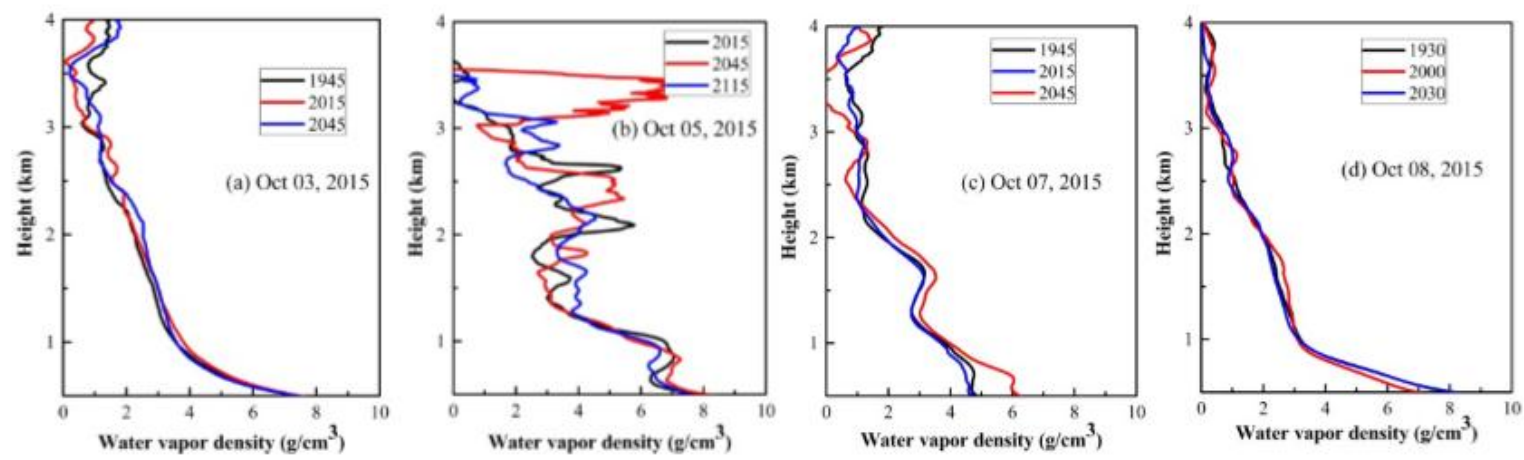

Figure 12. Several representative atmospheric water vapor density profiles during the rainfall process of 1-10 October 2015.

The left Figure 12a presents the profiles of 19:45, 20:15, and 20:45 CST on 3 October; water vapor density decreases sharply with height, and there are small fluctuations in the height range of $3-4 \mathrm{~km}$. Different profiles and variation characteristics can be observed on 5 October, as shown in Figure 12b. Regarding vertical variation, water vapor changes rapidly with height, and there also exist several water vapor layers with fast change in the height range of $1.5-3.5 \mathrm{~km}$ at different times. That is to say, vertical change in water vapor is intensified and water vapor layers are also changed rapidly during onsets of rainfall. Furthermore, it is shown that water vapor density below $1 \mathrm{~km}$ is obviously enhanced and aggregated, reflecting the accumulation of water vapor and precipitation for the forthcoming rainfall on October 6. Figure 12c showed the profiles of 19:45, 20:15, and 20:45 CST on 7 October, the first day after rainfall, and the water vapor profiles presented a relatively steady decline trend with water vapor layers, indicating the slowing down change with time. As the weather clears up, water vapor also presents a rapidly decreasing trend of with height.

Figure 13 presents the time series of the lidar PWV during the process. Obvious changes can be observed in lidar PWV as the weather changed from clear to rainy and again to clear during the process. The PWV was valued at $10 \mathrm{~mm}$ on 1 October under clear weather conditions, and gradually increased to $20 \mathrm{~mm}$ until 5 October under overcast weather. The lidar PWV was absent on 6 October because of moderate rainy weather throughout the day, and the corresponding average precipitation was $8 \mathrm{~mm}$. It reached a value of $17 \mathrm{~mm}$ on 7 October after light rain in the daytime and then slowed to less than $10 \mathrm{~mm}$ during a change from overcast to clear weather during 8-10 October.

For purposes of comparison, the surface water vapor density was obtained by using temperature and relative humidity from the ground meteorological station, and the results are also shown in Figure 13. It can be seen that the surface water vapor density also showed a gradual increase trend, and it reached the maximum with a value of about $12 \mathrm{~g} / \mathrm{cm}^{3}$ on 5 October, and then remained stable with a value of $12-14 \mathrm{~g} / \mathrm{cm}^{3}$ during the whole day of 6 October. After the rain, the surface water vapor density gradually decreased during 7 and 8 October, and a slight increase appeared on 9 October, before beginning to drop again to a value of $6 \mathrm{~g} / \mathrm{cm}^{3}$. It is thus clear that lidar PWV has a good consistency with the surface water vapor density during the whole rainfall process. Therefore, lidar PWV underwent a long preparatory period before the rainfall, and decreased gradually after the rainfall. 


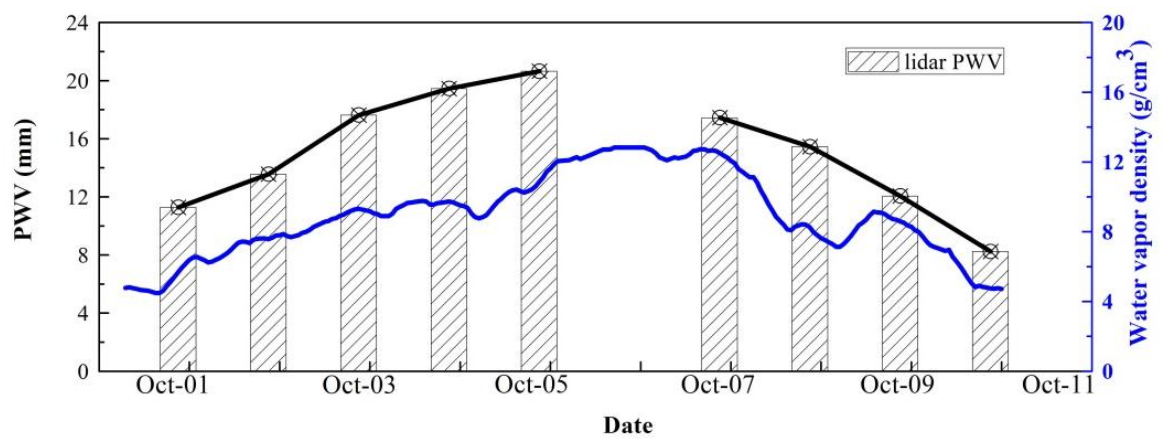

Figure 13. Time series of the lidar PWV and surface water vapour density during 1-10 October 2015.

The synchronous time series of metrological parameters, including relative humidity, vapor pressure and DTD, are shown in Figure $14 \mathrm{a}-\mathrm{c}$, and the corresponding change rates are also given. Before and after rainfall, it is clearly seen that both vapor pressure and DTD showed trends of obvious diurnal changes, with maxima at midday and minima at night. Meanwhile, the opposite diurnal trend was observed in relative humidity, with highs at night and lows at midday. However, obviously different change trends were found in these metrological parameters during the rainfall. They all showed a stable trend and less change. The relative humidity was stable and remained within a range of $80-100 \%$. The vapor pressure and DTD were both steady and less variable. The vapor pressure was approximately $20 \mathrm{hPa}$, and DTD was less than $2 \mathrm{~K}$. The corresponding change rates can also reflect the variation trend of these metrological parameters. An obvious trend in change rate can be seen for individual parameters before and after rainfall. The change rate is within the range of $-3 \mathrm{~K}$ to $+3 \mathrm{~K}$ per hour for DTD, in the scope of $-3 \mathrm{hPa}$ to $+3 \mathrm{hPa}$ per hour for vapor pressure, and -10 to $10 \%$ per hour for relative humidity before and after rainfall. However, these meteorological parameters are accompanied with stable trends with change rate of close to 0 in the rainfall processes. Therefore, higher and stable humidity, lower and stable vapor pressure and dew-point temperature differences were found to accompany the rainfall processes.
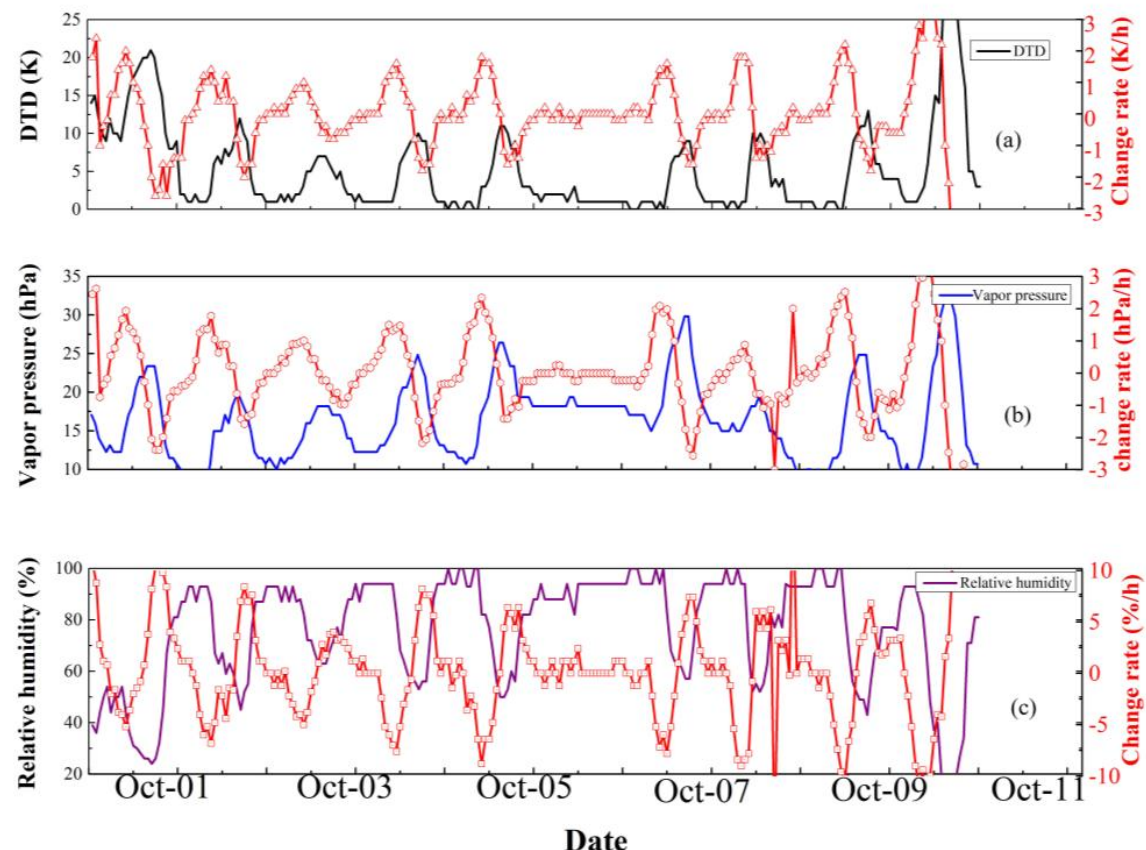

Figure 14. Time series of meteorological parameters and the corresponding change rates during rainfall case. (a) dew-point temperature difference; (b) vapor pressure; (c) relative humidity. 
Furthermore, correlation analysis between lidar PWV and the above metrological parameters are also investigated. Positive correlation can be obtained between lidar PWV and the surface water vapor density with a high correlation coefficient of 0.856 , as shown in Figure 15a. Figure 15b-d presented the positive correlation between lidar PWV with relative humidity, temperature and vapor pressure, with correlation coefficients of $0.79,0.561$ and 0.7382 , respectively. It should to be noted that PWV and relative humidity are positively related due to the small range of temperature at different nights. As for DTD, negative correlation can be found between lidar PWV and DTD with a coefficient of -0.1770 , which is mainly because of the small range of temperature and DTD on different nights.
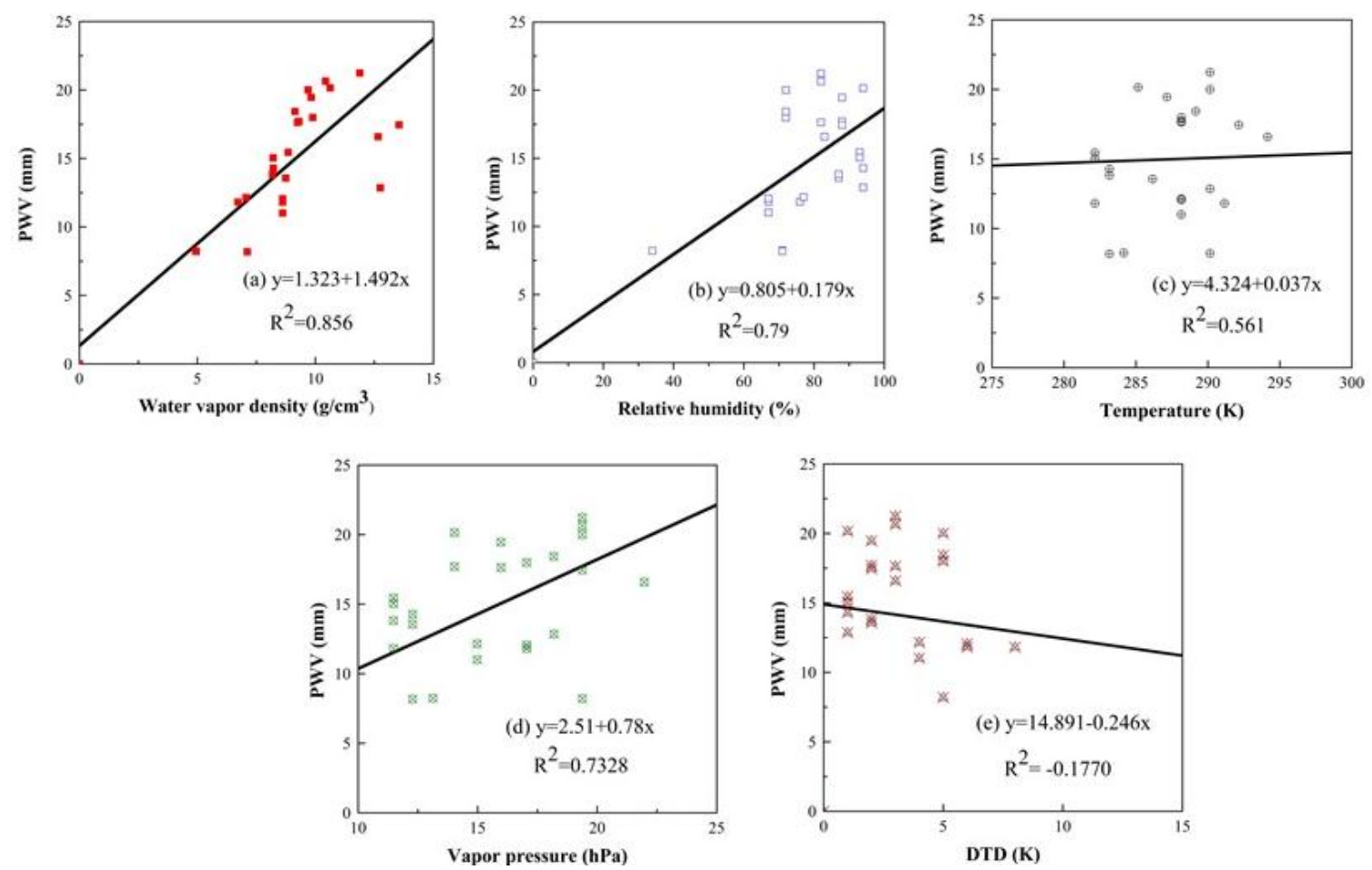

Figure 15. Correlation analysis between PWV and meterological parameters during the rainfall case.

Therefore, lidar detection can capture the intensifying vertical change characteristics of water vapor, and thus, make the accumulation of perceptible water vapor in the lower troposphere before rainfall. Synchronized meteorological parameters are accompanied with stable trends, with change rates of close to 0 in the rainfall processes. They also show a high correlation with lidar PWV. Thus, with the advantage of lidar detection, investigation of water vapor profiles and PWV by Raman lidar and the comprehensive correlation analyses with synchronic meteorological parameters can prove to be good indications of rainfall.

\section{Summary and Discussion}

Retrieved water vapor mixing ratio profiles by Raman lidar were used to calculate the PWV in different layers. The obtained lidar and radiosonde PWV were compared, and it was verified that the Raman lidar can be used to measure PWV with high precision. We discussed the variation and distribution characteristics of PWV in Xi'an and found that different proportions of PWV existed in different layers, and the PWV in each layer presented consistent seasonal variations, being relatively rich in summer, less so in spring and autumn, and relatively deficient in winter.

Furthermore, after studying the monthly mean values of meteorological parameters and lidar PWV data, comparisons of lidar PWV and meteorological parameters were studied in detail, and the correlations between them were also explored. The results show that water vapor pressure and 
surface temperature showed the same inter-seasonal oscillations as PWV, with a monthly mean correlation coefficient of $\sim 0.90$. However, incomplete synchronizations of the seasonal trends in PWV and humidity were revealed such that humidity reached its minimum values in spring and winter, and higher humidity appeared in the late summer and beginning of autumn of each year.

Taking the advantage of lidar detection, atmospheric water vapor density profiles and the obtained PWV by Raman lidar are discussed employing a rainfall case. The intensifying characteristics of vertical change in water vapor and the accumulation of PWV in the lower troposphere can be captured before the onset of rainfall. In addition, time series of lidar PWV and meteorological parameters are also investigated in detail. It can be clearly found that meteorological parameters such as water vapor pressure, relative humidity, and dew-point temperature difference showed obvious diurnal change trends before the onset of rainfall. However, in rainfall processes, stable and higher humidity, and stable and lower variations in water vapor pressure and dew-point temperature difference were instead accompanied with change rates of close to 0 . Also, obvious correlations were also found between lidar PWV and these meteorological parameters during the entire process. Therefore, the intensifying characteristics of vertical change in water vapor, the gradual growth in PWV by Raman lidar, and the high correlated variations in synchronized surface meteorological parameters can prove to be good indications of rainfall.

Author Contributions: Conceptualization, Y.W., L.T., T.G. and D.H. Methodology, Y.W., L.T. and D.H. Resources, Y.W., L.T., Z.J., T.G. and Q.W. Original draft preparation, Y.W. and L.T. Writing, Y.W. and L.T. Review and editing, Y.W., Y.S. and D.H. Visualization, Z.J., T.G., Q.W. Supervision, Y.W. and D.H. Project administration, Y.W., Y.S. and D.H. Funding acquisition, Y.W. and D.H.

Funding: This work was supported by the National Natural Science Foundation of China (NSFC) (grant No. U1733202, 41627807, 41575027 and 41027004).

Conflicts of Interest: The authors declare no conflict of interest.

\section{References}

1. King, M.D.; Menzel, W.P.; Kaufman, Y.J.; Tanré, D.; Gao, B.C.; Platnick, S.; Ackerman, S.A.; Remer, L.A.; Pincus, R.; Hubanks, P.A. Cloud and aerosol properties, precipitable water, and profiles of temperature and humidity from MODIS. IEEE Trans. Geosci. Remote Sens. 2003, 41, 442-458. [CrossRef]

2. Panwar, V.; Jain, A.R.; Goel, A.; Mandal, T.K.; Rao, V.R.; Dhaka, S.K. Some features of water vapor mixing ratio in tropical upper troposphere and lower stratosphere: Role of convection. Atmos. Res. 2012, 108, 86-103. [CrossRef]

3. Wang, C.; Gao, S.; Liang, L.; Deng, D.; Gong, H. Multi-scale characteristics of moisture transport during a rainstorm process in North China. Atmos. Res. 2014, 145, 189-204. [CrossRef]

4. Divakarla, M.G.; Barnet, C.D.; Goldberg, M.D.; McMillin, L.M.; Maddy, E.; Wolf, W.; Zhou, L.; Liu, X. Validation of Atmospheric Infrared Sounder temperature and water vapor retrievals with matched radiosonde measurements and forecasts. J. Geophys. Res. 2006, 111, D09S15. [CrossRef]

5. Li, Z.; Muller, J.P.; Cross, P. Comparison of precipitable water vapor derived from radiosonde, GPS, and Moderate-Resolution Imaging Spectroradiometer measurements. J. Geophys. Res. 2003, 108, 4651. [CrossRef]

6. Sharifi, M.A.; Khaniani, A.S.; Joghataei, M. Comparisons of GPS precipitable water vapor and meteorological parameters during rianfalls in Tehran. Meterol. Atmos. Phys. 2015, 127, 701-710. [CrossRef]

7. Sohn, D.H.; Park, K.D.; Won, J.H.; Cho, J.H.; Roh, K.M. Comparison of the Characteristics of Precipitable Water Vapor Measured by Global Positioning System and Microwave Radiometer. J. Astron. Space Sci. 2012, 29, 1-10. [CrossRef]

8. Wang, J.; Zhang, L. Systematic errors in global Radiosonde Precipitable Water Data from Comparisons with Ground-Based GPS Measurements. J. Clim. 2008, 21, 2218-2238. [CrossRef]

9. Halthore, R.N.; Eck, T.F.; Holben, B.N.; Markham, B.L. Sun photometric measurements of atmospheric water vapor column abundance in the 940-nm band. J. Geophys. Res. 1997, 102, 4343-4352. [CrossRef] 
10. Pérez-Ramírez, D.; Navas-Guzmán, F.; Lyamani, H.; Fernández-Gálvez, J.; Olmo, F.J.; Alados-Arboledas, L. Retrievals of precipitable water vapor using star photometry: Assesment with Raman lidar and link to Sun photometry. J. Geophys. Res. 2012, 117, D05202. [CrossRef]

11. Jia, J.; Yi, F. Atmospheric temperature measurements at altitudes of 5-30 km with double-grating-based pure rotational Raman lidar. Appl. Opt. 2014, 53, 5330-5343. [CrossRef] [PubMed]

12. Wang, Y.; Cao, X.; He, T.; Gao, F.; Hua, D.; Zhao, M. Observation and analysis of the temperature inversion layer by Raman lidar up to the lower stratosphere. Appl. Opt. 2015, 54, 10079-10088. [CrossRef] [PubMed]

13. Behrendt, A.; Nakamura, T.; Onishi, M.; Baumgart, R.; Tsuda, T. Combined Raman lidar for the measurement of atmospheric temperature, water vapor, particle extinction coefficient, and particle backscatter coefficient. Appl. Opt. 2002, 41, 7657-7666. [CrossRef] [PubMed]

14. Whiteman, D.N. Examination of the traditional Raman lidar technique. II. Evaluating the ratios for water vapor and aerosol. Appl. Opt. 2003, 42, 2593-2608. [CrossRef] [PubMed]

15. Xie, C.B.; Zhou, J.; Yue, G.M.; Qi, F.D.; Fan, A.Y. Mobile lidar system for measuring tropospheric aerosol and water vapor. Infrared Laser Eng. 2007, 36, 365-367. (In Chinese)

16. Froidevaux, M.; Higgins, C.W.; Simeonov, V.; Ristori, P.; Pardyjak, E.; Serikov, I.; Calhoun, R.; Van Den Bergh, H.; Parlange, M.B. A Raman lidar to measure water vapor in the atmospheric boundary layer. Adv. Water Res. 2013, 51, 345-356. [CrossRef]

17. Yufeng, W.; Qiang, F.; Meina, Z.; Fei, G.; Huige, D.; Yuehui, S.; Dengxin, H. A UV multifunctional Raman lidar system for the observation and analysis of atmospheric temperature, humidity, aerosols and their conveying characteristics over Xi'an. J. Quant. Spectrosc. Radiat. Transf. 2018, 205, 114-126. [CrossRef]

18. Leblanc, T.; Walsh, T.D. Ground-based water vapor Raman lidar measurements up to the upper troposphere and lower stratosphere for long-term monitoring. Atmos. Meas. Tech. 2012, 5, 17-36. [CrossRef]

(C) 2018 by the authors. Licensee MDPI, Basel, Switzerland. This article is an open access article distributed under the terms and conditions of the Creative Commons Attribution (CC BY) license (http:/ / creativecommons.org/licenses/by/4.0/). 